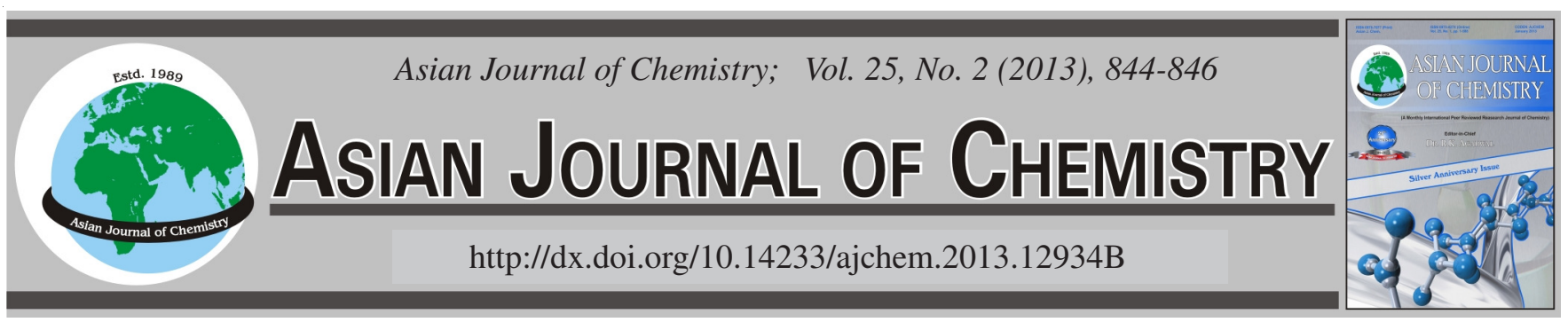

\title{
Synthesis of Spinal Lithium-Titanium Oxide Lithium \\ Ion-Sieve by Solid State Reaction Crystallization Method
}

\author{
JINHE JIANG
}

Department of Chemistry and Chemical Engineering, MicroScale Science Institute, Weifang University, Weifang 261061, P.R. China

Corresponding author: Fax: +86 536 8785802; Tel: +86 536 8785802; E-mail: jiangjinhe2006@ 163.com

The $\mathrm{Li}_{3} \mathrm{Ti}_{1.25} \mathrm{O}_{4}$ was synthesized by a solid state reaction crystallization method using lithium carbonate and titanium dioxide as raw materials. The optimum conditions were obtained by thermal experiment, calcination temperature was $775^{\circ} \mathrm{C}$, calcination time was $4.5 \mathrm{~h}$. The characterization results showed that the exchange capacity of $\mathrm{Li}^{+}$was $9.3 \mathrm{mmol} \mathrm{g}^{-1}$ for $\mathrm{Li}^{+}$in the solution.

Key Words: Solid state reaction crystallization method, Spinel-type metal oxides, $\mathrm{Li}_{3} \mathrm{Ti}_{1.25} \mathrm{O}_{4}$.

\section{INTRODUCTION}

Lithium and its compounds have widely been applied in the aerospace, chemical industry, medicine, air conditioning, thermonuclear reactions and high-energy batteries, the demand of lithium and its compounds will be increased quickly. There are very rich liquid lithium resources in China, It is important to exploit and use the resources of lithium. The methods of extracting lithium from salt water resources, such as salt lake water, the underground brine, salt mother liquid, oil and gas field water have carbonate precipitation method, ion exchange and adsorption method, extraction method. Among which were simple, recovery and selectivity methods of ion exchange and adsorption. They have greater advantages than other methods. It is significance to extraction lithium from a dilute solution by using ion exchange and adsorption methods. This approach is to find an exchange agent with specific selectivity and memory for lithium ion. The appearance of ion memory inorganic materials (ion sieve) became possible direct extracting lithium from the above-mentioned resources. Preparation methods of this exchange agent are sol-gel synthesis, hydrothermal synthesis and high-temperature solid-phase synthesis method ${ }^{1,2}$. In this paper, inorganic ion exchanger $\left(\mathrm{Li}_{3} \mathrm{Ti}_{1.25} \mathrm{O}_{4}\right)$ with a spinel structure ion memory was synthesized by solid state reaction crystallization method, which is different the reported in the literatures ${ }^{3,4}$ and its ion-exchange properties were studied.

\section{EXPERIMENTAL}

$\mathrm{Li}_{2} \mathrm{CO}_{3}$ and $\mathrm{TiO}_{2}$ were all analytical reagents; pure ethanol; D/max-A type X-ray diffraction instrument; Dx-170 type ion chromatogram instrument; XQM planetary ball mill; AA-670 atom absorption spectrum instrument; tubular-furnace.

Synthesis and characterization of $\mathrm{Li}_{3} \mathrm{Ti}_{1.25} \mathrm{O}_{4}$ : The pure ethanol was dropped into a XQM planetary ball mill mixed powder of $\mathrm{Li}_{2} \mathrm{CO}_{3}$ and $\mathrm{TiO}_{2}$ with a $\mathrm{Li} / \mathrm{Ti}$ mole ration of 3:1.25 at the condition of constant rate churning. After $8 \mathrm{~h}$, the mixture was mixed completely. After mixing fully, the mixture was pressed to tablet by tablet press machine. Then the tablet was heat-treated for $4.5 \mathrm{~h}$ at $775^{\circ} \mathrm{C}$ to obtain the Li-Ti oxide, the sample was designed as $\mathrm{LiTiO}-775$, whose theoretical formula was $\mathrm{Li}_{3} \mathrm{Ti}_{1.25} \mathrm{O}_{4}$. Then it was analyzed of X-ray diffraction and compared to literature ${ }^{3,4}$.

Composition analysis: A $0.2 \mathrm{~g}$ portion of sample was dissolved with acid. The $\mathrm{Li}$ and $\mathrm{Ti}$ contents were determined by atomic absorption spectrometry.

Cation extraction of LiTi oxide and acid modification: Four $0.200 \mathrm{~g}$ portions of sample (LiTiO-775 oxides) were immersed in $\mathrm{HNO}_{3}$ solution $(50 \mathrm{~mL})$ of $0.01,0.1,1.0$ and $10.0 \mathrm{M}$, respectively with shaking in constant temperature water at $25^{\circ} \mathrm{C}$. After 3 days, take the supernatant solution to determine the cation concentration, test its acid proof ability and the extraction ration of $\mathrm{Li}^{+}, \mathrm{Ti}^{4+}$.

A $5 \mathrm{~g}$ portion of sample (LiTiO-775) was immersed in a $1 \mathrm{M} \mathrm{HNO}_{3}$ solution $(500 \mathrm{~mL})$ with intermittent shaking in constant temperature water at $25^{\circ} \mathrm{C}$. After 7 days, remove the supernatant solution and add new $\mathrm{HNO}_{3}$ solution. Repeating that for twice, then the initial sample was transformed to H-type sample, washed with water and air-dried. The sample obtained by thermal crystallized at $775^{\circ} \mathrm{C}$ and acid modified was designated as LiTiO-775(H). The composition was deter- 
mined by the atomic absorption spectrometry and the $\mathrm{H}^{+}$ content was calculated by subtraction method.

Saturation capacity of exchange: Weigh five $0.5 \mathrm{~g}$ portions of LiTiO-775(H), then each portion was immersed in a $0.1 \mathrm{M}$ solution $(10 \mathrm{~mL})$, containing $\mathrm{Li}^{+}, \mathrm{Na}^{+}, \mathrm{K}^{+}, \mathrm{Rb}^{+}$and $\mathrm{Cs}^{+}$, respectively, diluted to $100 \mathrm{~mL}$, shaken in constant temperature water at $25^{\circ} \mathrm{C}$. After saturation exchanging ${ }^{3,4}$ (namely, after 10 days the solutions were filtered by subminiature aperture sieve and the cation concentration was determined. At the same time, do vacant experiment. Last, the inorganic exchanger saturation capacity of exchange for alkali-metalions obtained by decrease quantity.

Distribution coefficient $\left(\mathbf{K}_{\mathbf{d}}\right)$ : After weighing four 0.100 $\mathrm{g}$ portions of LiTiO-775(H), each portion of sample was immersed in a $0.05 \mathrm{M}$ mixed solution $(0.200 \mathrm{~mL})$ containing $\mathrm{Li}^{+}, \mathrm{Na}^{+}, \mathrm{K}^{+}, \mathrm{Rb}^{+}$and $\mathrm{Cs}^{+}\left(\mathrm{Cl}^{-} / \mathrm{OH}^{-}\right.$rations are different in each solution, $\mathrm{C}\left(\mathrm{Cl}^{-}\right)+\mathrm{C}\left(\mathrm{OH}^{-}\right)=0.1 \mathrm{M}, \mathrm{C}=\mathrm{Li}^{+}, \mathrm{Na}^{+}, \mathrm{K}^{+}, \mathrm{Rb}^{+}$and $\left.\mathrm{Cs}^{+}\right)$. The alkali-metals ions total concentration all was $1.0 \times$ $10^{-3} \mathrm{M}$ by adding $9 \mathrm{~mL}$ distilled water. After the samples were shaken for 7 days in constant temperature water at $25^{\circ} \mathrm{C}$ and were filtered, cation concentrations in each samples were obtained.

\section{RESULTS AND DISCUSSION}

Compound and appraisement of $\mathrm{Li}_{3} \mathrm{Ti}_{1.25} \mathrm{O}_{4}$ : The X-ray diffraction pattern of compound metal oxide $\left(\mathrm{Li}_{3} \mathrm{Ti}_{1.25} \mathrm{O}_{4}\right)$, crystallized was shown in Fig. 1. The structure of compound metal oxide $\mathrm{Li}_{3} \mathrm{Ti}_{1.25} \mathrm{O}_{4}$ crystallized at $775^{\circ} \mathrm{C}$ was much perfect.

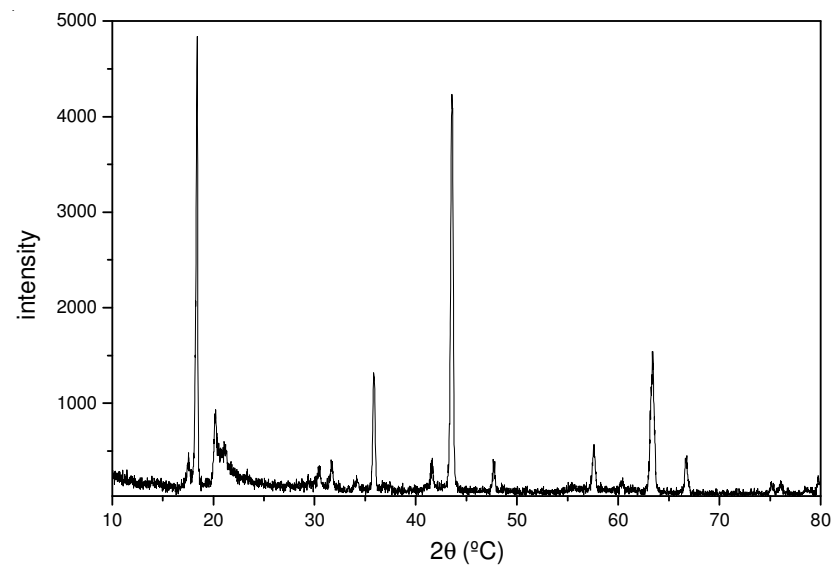

Fig. 1. Powder's X-ray figures of $\mathrm{Li}_{2.95} \mathrm{Ti}_{1.22} \mathrm{O}_{3.95}$ crystal

We know from chemical analysis, the composition of LiTiO-775 is $\mathrm{Li}_{2.95} \mathrm{Ti}_{1.22} \mathrm{O}_{3.95}$, whose chemical component is basically corresponded with the composition of spinel-type metal oxides.

Cation extraction of compound oxide $\mathrm{LiTiO}$ and acid modification: The extraction ration of $\mathrm{Li}^{+}$and $\mathrm{Ti}^{4+}$ from $\mathrm{LiTiO}-$ 775 in different concentration $\mathrm{HNO}_{3}$ solution is shown in Fig. 2. We know from Fig. 2, the extractabilities of $\mathrm{Li}^{+}$are $47-89 \%$ and $\mathrm{Ti}^{4+}$ are $2.7-6.6 \%$. Those indicate that the extractabilities of $\mathrm{Li}^{+}$are higher than $\mathrm{Ti}^{4+}$ when exchanger was immersed in $1 \mathrm{M}$ acid solution, corresponding with the exchanger condition was better $\left(1 \mathrm{~N}, \mathrm{Li}^{+} 82 \%, \mathrm{Ti}^{4+} 5.4 \%\right)$.

The analysis indicate the composition of LiTiO-775(H) was $\mathrm{H}_{2.42} \mathrm{Li}_{0.53} \mathrm{Ti}_{1.15} \mathrm{O}_{3.74}$, whose component of $84 \% \mathrm{Li}^{+}$

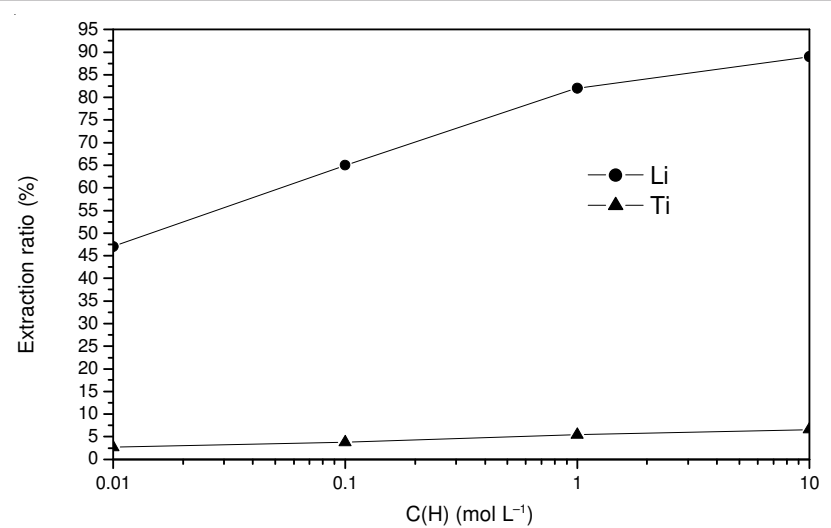

Fig. 2. Extraction ratio of cations from LiTiO-775 in nitric acid solution

transformed to $\mathrm{H}^{+}$compared with the composition $\mathrm{Li}_{2.95} \mathrm{Ti}_{1.22} \mathrm{O}_{3.95}$ before acid-treated. Then the specific $\mathrm{Li}^{+}$of exchanger were extracted fulfill basically and remained the H-type identified with initial type.

Saturation capacity of exchange: The relation between radius and saturated ion exchange capacity of LiTiO-775 $(\mathrm{H})$ for alkali was shown in Fig. 3. Known from Fig. 3, the capacity of exchange for $\mathrm{Li}^{+}$was much higher than those for other alkali ions. The capacity for $\mathrm{Li}^{+}$is $9.3 \mathrm{mmol} \mathrm{g}$. It proved that the ion exchange synthesized has higher capacity of exchange and better remembering of exchange for $\mathrm{Li}^{+}$. The effect factors of saturation capacity of exchange of LiTiO-775 $(\mathrm{H})$ are: The $\mathrm{Li}^{+}$in exchange solution must be removed previously, because $\mathrm{Li}^{+}$exchanged with exchanger vacancy site when existing too much $\mathrm{Li}^{+}$. The experimental results shown that the exchange capacity of ion exchanger for $\mathrm{Li}^{+}$is much higher than those for other alkali ions in thin solution, which indicate that the ion-exchange reaction is carried out between and bare ions. At the time of exchange, a $\mathrm{Li}^{+}$was replaced by one $\mathrm{H}^{+}$. $\mathrm{Li}^{+}$not only entered the vacancy site but also exchanged with the $\mathrm{H}^{+}$ of surface. Therefore, LiTiO-775 $(\mathrm{H})$ has a higher exchange capacity for $\mathrm{Li}^{+}$.

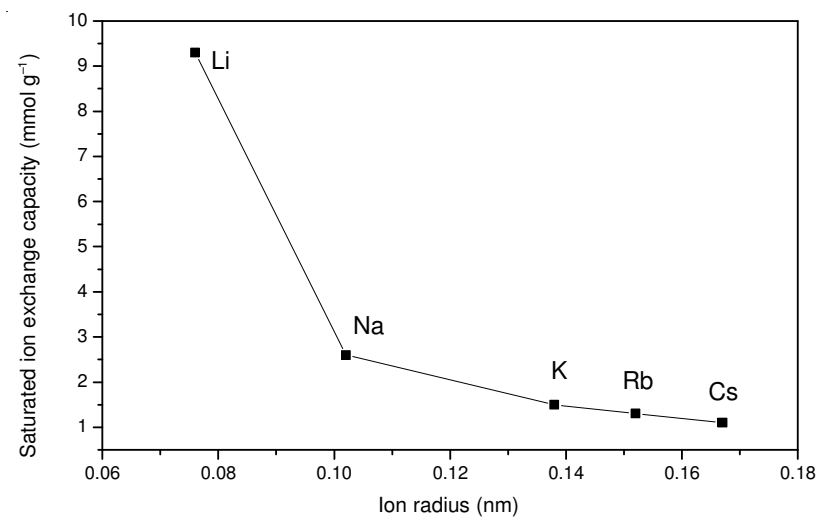

Fig. 3. Relation between ion radius and saturated ion exchange capacity of LiTiO-775(H)for alkali ions

Distribution coefficient $\left(\mathbf{K}_{\mathbf{d}}\right)$ : $\mathrm{K}_{\mathrm{d}}$ values can be the token of exchange selectivity of LiTiO-775 $(\mathrm{H})$ for correlate ions. Shown in Fig. 4, $\mathrm{K}_{d}$ values of LiTiO-775 $(\mathrm{H})$ for alkali ions are larger and larger with an increase $\mathrm{pH}$ over the $\mathrm{pH}$ region studied. The selectivity sequence of LiTiO-775(H) for alkali metal ions as follows: 


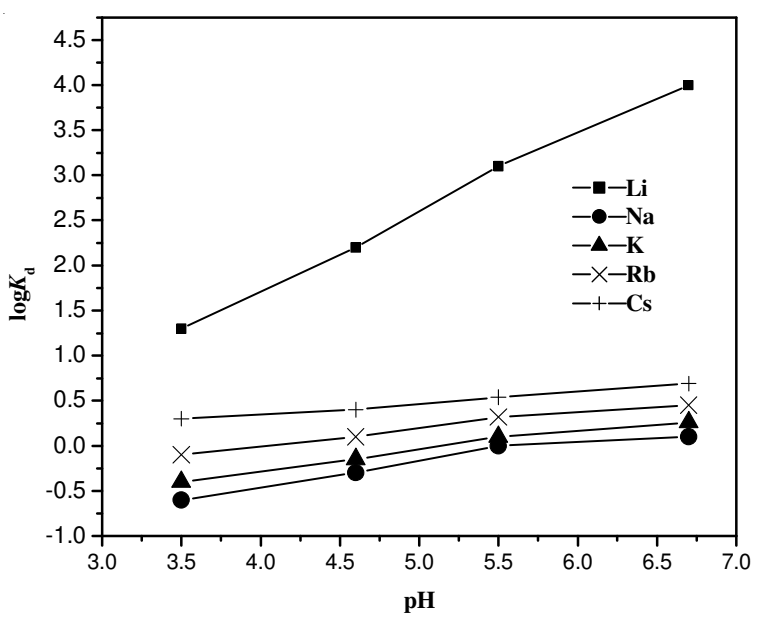

Fig. 4. Distribution coefficient of LiTiO-775(H)for alkali ions

$$
\mathrm{Li}^{+}>\mathrm{Cs}^{+}>\mathrm{Rb}^{+}>\mathrm{K}^{+}>\mathrm{Na}^{+}
$$

It indicates that LiTiO-775 $(\mathrm{H})$ has a better ion selectivity for $\mathrm{Li}^{+}$. Ion-exchange reaction is reversible reaction. The reaction of $\mathrm{H}^{+}$in ion-exchanger with alkali metal ions in solution as follows (example for $\mathrm{Li}^{+}$):

$$
\mathrm{E}-\mathrm{H}+\mathrm{Li}^{+} \rightleftharpoons \mathrm{E}-\mathrm{Li}+\mathrm{H}^{+}
$$

\section{Conclusion}

The comprehensive results indicate that the $\mathrm{Li}_{3} \mathrm{Ti}_{1.25} \mathrm{O}_{4}$ of spinel-type metal oxide show a capacity extraction/insertion of $\mathrm{Li}^{+}$in the aqueous phase, mainly by an ion-exchange mechanism. The $\mathrm{Li}^{+}$-extracted samples show a high selectivity and a large capacity for $\mathrm{Li}^{+}$among alkali metal ions.

\section{REFERENCES}

1. Y.F. Liu, Q. F and K. Ooi, J. Ion Exchange Adsorption, 11, 216 (1995).

2. Z.S. Peng, Y.S. Yan, C.Y. Jiang, C.R. Wan and H.C. Gao, J. Chem. Online, 12, 11 (1997)

3. J.H. Jiang, D.Q. Dong and J.L. Li, J. Chin. J. Appl. Chem., 23, 357 (2006).

4. H. Zhong, J. Chin. J. Appl. Chem., 17, 307 (2000). 